\title{
Experimental investigation on heat transfer rate of Co-Mn ferrofluids in external magnetic field
}

\author{
M. Margabandhu ${ }^{1 *}$, S. Sendhilnathan ${ }^{2}$, S. Senthilkumar $^{3}$, K. Hirthna $^{4}$ \\ ${ }^{1}$ Anna University Chennai: University College of Engineering-Ariyalur, Department of Physics, Ariyalur-621704, India \\ ${ }^{2}$ Anna University Chennai: University College of Engineering-Pattukkottai, Department of Physics, \\ Rajamadam-614701, Thanjavur, India \\ ${ }^{3}$ Anna University Chennai: University College of Engineering-Ariyalur, Department of EEE, Ariyalur-621704, India \\ ${ }^{4}$ Anna University Chennai: University College of Engineering-Kanchipuram, Department of Physics, \\ Kanchipuram-631552, India
}

\begin{abstract}
Manganese substituted cobalt ferrite $\left(\mathrm{Co}_{1-\mathrm{x}} \mathrm{Mn}_{\mathrm{x}} \mathrm{Fe}_{2} \mathrm{O}_{4}\right.$ with $\mathrm{x}=0,0.3,0.5,0.7$ and 1) nanopowders were synthesized by chemical coprecipitation method. The synthesized magnetic nanoparticles were investigated by various characterization techniques, such as X-ray diffraction (XRD), vibrating sample magnetometry (VSM), scanning electron microscopy (SEM) and thermogravimetric and differential thermal analysis (TG/DTA). The XRD results confirmed the presence of cubic spinel structure of the prepared powders and the average crystallite size of magnetic particles ranging from 23 to $45 \mathrm{~nm}$. The VSM results showed that the magnetic properties varied with an increase in substituted manganese while SEM analysis showed the change in the morphology of obtained magnetic nanoparticles. The TG/DTA analysis indicated the formation of crystalline structure of the synthesized samples. The heat transfer rate was measured in specially prepared magnetic nanofluids (nanoparticles dispersed in carrier fluid transformer oil) as a function of time and temperature in presence of external magnetic fields. The experimental analysis indicated enhanced heat transfer rate of the magnetic nanofluids which depended upon the strength of external magnetic field and chemical composition.
\end{abstract}

Keywords: magnetic nanoparticles; coprecipitation; magnetic fluids; rate of heat transfer; carrier fluid

(C) Wroclaw University of Technology.

\section{Introduction}

Nanomaterials have been produced and used by humans since time immemorial. The existence of beautiful ruby red color in some ancient glass paintings and the luster deposited on some medieval pottery contain metallic spherical nanoparticles dispersed in complex way. The techniques of synthesis and deposition were a closely guarded secret and have not been completely understood even now. The modernized microscopic analysis paved way to identification and characterization of nanomaterials and the correlation of their peculiar behavior with their structure [1]. Ferrofluids are the fluids possessing magnetic nanoparticles dispersed in various non-polar or polar liquid media which have been coated by various surfactants,

*E-mail: mmargabandhu@yahoo.co.in such as oleic acid, dodecylamine, sodium carboxymethyl cellulose. These surfactants have been used to improve the stability and to prevent the agglomeration of the particles [2]. Heat transfer is one of important properties of ferrofluids which plays a vital role in various fields, such as aerospace, mechanical engineering, bio-engineering, pressure sensors, loud speaker coolants and smart cooling devices [3]. In metal and metal oxide nanoparticles dispersed in carrier fluids, the heat transfer rate is high as compared to conventional fluids, such as water, vacuum pump fluid, engine oil and ethylene glycol [4]. The heat transfer rate in nanofluids is dramatically increased due to the application of external magnetic field because of the effective heat conduction through the chain like structures of magnetic nanoparticles [5]. Nkurikiyimfura et al. [6] reported in his review paper about the use of magnetic nanofluids in heat transfer medium 
in detail by controlling parameters such as particle size distribution, particle coating, particle clustering, cluster morphology, particles flow, particle orientation and the influence of external magnetic field on heat transfer rate. Hong et al. [7] showed that different volume fractions of iron nanoparticles in ethylene glycol were responsible for the determination of thermal conductivity in nanofluids. Shima et al. [8] conducted a series of experiments and confirmed that the excellent heat transfer rate of magnetically polarizable nanofluid was due to the efficient heat transport through percolating nanoparticle paths. Further, these experiments showed that the maximum progress in heat transfer rate of ferrofluids was caused by the nonagglomerated nanoparticles dispersed in the ferrofluids. The heat transfer rate in ferrofluids can be tuned from low to high value by varying the application of external magnetic field and its applied direction [9]. For the last two decades, magnetic nanoparticles and ferrofluids have been studied as the most fascinating topics in heat transport phenomena and in different applications. The present work was carried out on synthesis and investigation of manganese substituted $\mathrm{CoFe}_{2} \mathrm{O}_{4}$ nanoparticles dispersed in carrier fluid transformer oil, subjected to external magnetic fields.

\section{Experimental}

\subsection{Materials}

The chemicals used for the preparation of magnetic nanoparticles and ferrofluids were transformer oil, sodium hydroxide pellets $(\mathrm{NaOH})$, cobalt chloride $\left(\mathrm{CoCl}_{2} \cdot 6 \mathrm{H}_{2} \mathrm{O}\right)$, manganese chloride $\left(\mathrm{MnCl}_{2} \cdot 4 \mathrm{H}_{2} \mathrm{O}\right)$ and ferric chloride $\left(\mathrm{FeCl}_{3} \cdot 6 \mathrm{H}_{2} \mathrm{O}\right)$. They were of very high purity ( $99 \%$ ) and were obtained from Merck and Nice chemicals. Hence, further purification process was not necessary.

\subsection{Synthesis}

\subsubsection{Magnetic nanoparticles}

Manganese substituted cobalt ferrite nanoparticles of different compositions $\left(\mathrm{Co}_{1-\mathrm{x}} \mathrm{Mn}_{\mathrm{x}} \mathrm{Fe}_{2} \mathrm{O}_{4}\right.$ with $\mathrm{x}=0,0.3,0.5,0.7$ and 1 ) were synthesized by coprecipitation technique. Aqueous solutions of chemicals $\mathrm{CoCl}_{2} \cdot 6 \mathrm{H}_{2} \mathrm{O}, \mathrm{MnCl}_{2} \cdot 4 \mathrm{H}_{2} \mathrm{O}$, $\mathrm{FeCl}_{3} \cdot 6 \mathrm{H}_{2} \mathrm{O}$, each of $100 \mathrm{~mL}$, were mixed in a boiling solution of $\mathrm{NaOH}(1000 \mathrm{~mL})$ at $65{ }^{\circ} \mathrm{C}$. The salt solutions in 1:2 molar ratios were added to the boiling $\mathrm{NaOH}(0.5 \mathrm{M})$ solution. The mixed solution was subjected to magnetic stirring for one hour under a constant temperature of $100{ }^{\circ} \mathrm{C}$. The stirring time $(1 \mathrm{~h})$ at a constant temperature $\left(100{ }^{\circ} \mathrm{C}\right)$ was high enough for the transformation of hydroxides into spinel ferrites. At the end, an appropriate amount of oleic acid was added to the boiling solution and this solution was subjected to stirring process for another one hour. The time duration was sufficient for preparation of coated manganese substituted cobalt ferrite nanoparticles. The residual solution was undisturbed for four hours to obtain precipitate. Then, the obtained precipitate was washed several times with deionized water. Further the product was washed with acetone to remove impurities and dried at room temperature $[10,11]$.

\subsubsection{Preparation of ferrofluids}

Manganese substituted cobalt ferrofluids were prepared by dispersing $4.5 \mathrm{~g}$ of coated manganese substituted cobalt ferrite $\left(\mathrm{Co}_{1-\mathrm{x}} \mathrm{Mn}_{\mathrm{x}} \mathrm{Fe}_{2} \mathrm{O}_{4}\right.$ with $\mathrm{x}=0,0.3,0.5,0.7$ and 1 ) nanopowders in $350 \mathrm{~mL}$ carrier fluid transformer oil. The homogenous stable solution was obtained by stirring the nanoparticles in the transformer oil at a constant speed for one hour. The coating of nanoparticles in the prepared ferrofluids prevented agglomeration of the particles caused by magnetic and van der Waals attraction forces. In addition, it provided strong electrostatic interparticle repulsion between the magnetic nanoparticles $[10,11]$. Thus, the prepared $\mathrm{Co}-\mathrm{Mn}$ ferrofluids were chemically stable.

\subsection{Heat transfer rate analysis}

The experimental arrangement for the investigation of heat transfer rate of manganese substituted cobalt ferrofluids $\left(\mathrm{Co}_{1-\mathrm{x}} \mathrm{Mn}_{\mathrm{x}} \mathrm{Fe}_{2} \mathrm{O}_{4}\right.$ with $\mathrm{x}=0,0.3,0.5,0.7$ and 1 ) in external magnetic fields is shown in Fig. 1. The experimental setup was constructed using an electromagnet, heater, thermometer and ferrofluid filled glass beakers. The electromagnet was designed so as to be able to accommodate with in $500 \mathrm{~mL}$ glass beakers. 
The electromagnet was connected to an AC power supply of $230 \mathrm{~V}(50 \mathrm{~Hz})$ through a rheostat to obtain variable current. Prepared ferrofluids of $350 \mathrm{~mL}$ volume fraction were used for heat transfer rate analysis. The heater was connected to an AC power supply of $230 \mathrm{~V}(50 \mathrm{~Hz})$ and kept immersed in the ferrofluid beakers for heating process. A thermometer kept inside the fluid beaker was used to estimate the heat transfer rate as a function of time. The electromagnet was used to produce external magnetic field. In this experimental procedure, the prepared ferrofluids of different molar ratios were heated inside the ferrofluid beakers with an applied external magnetic field generated by the electromagnet through the current flow of I $=1.8 \mathrm{~A}$ and $2.7 \mathrm{~A}$. The heat transfer rates per temperature of ferrofluid were recorded and analyzed.

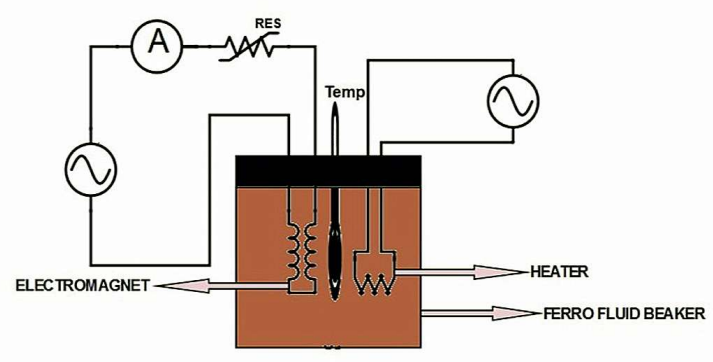

Fig. 1. Schematic setup for the investigation of heat transfer rate of $\mathrm{Co}-\mathrm{Mn}$ ferrofluids in external magnetic field.

\section{Characterization}

\subsection{X-ray diffraction}

X-ray diffraction (XRD) analysis of the synthesized powder samples was carried out at room temperature by using XPERT PRO X-ray powder diffractometer with $\mathrm{CuK} \alpha(\lambda=1.54060 \AA)$ radiation. The step size of $0.05^{\circ}$ in $2 \theta$ range and scan step time of $10 \mathrm{~s}$ were applied in the XRD measurements. Debye-Scherrer formula was used to calculate the average crystallite size of the synthesized samples [12]:

$$
D_{X r d}=\frac{0.89 \lambda}{\beta \cos \theta}
$$

$\lambda$ represents wavelength of $\mathrm{X}$-ray in $\AA, \beta$ is full width half maximum (FWHM in radians in the $2 \theta$ scale), $\theta$ represents the Bragg's diffraction angle, $\mathrm{D}_{\text {XRd }}$ is crystallite size in $\mathrm{nm}$.

\subsection{Vibrating sample magnetometer}

Hysteresis curves were obtained for the powder samples using vibrating sample magnetometer (VSM) at room temperature (Model: Lakeshore 7404) with an applied magnetic field of $20000 \mathrm{G}$. Magnetic parameters, such as coercivity $\left(\mathrm{H}_{\mathrm{c}}\right)$, remanent magnetization $\left(\mathrm{M}_{\mathrm{r}}\right)$ and saturation magnetization $\left(\mathrm{M}_{\mathrm{s}}\right)$ were found from the obtained measurements.

\subsection{SEM studies}

Scanning electron microscope (SEM) observations were made to visualize the morphology, homogeneity and composition of the prepared magnetic nanoparticles. The differences in size obtained by the XRD analysis and SEM studies were compared and analyzed.

\subsection{TG/DTA analysis}

Thermogravimetric (TG) and differential thermal analysis (DTA) were made using the instrument NETZSCH STA 449F3 in air atmosphere at a heating rate of $10^{\circ} \mathrm{C}$ per minute.

\section{Results and discussion}

\subsection{XRD characterization}

The X-ray diffraction (XRD) patterns of manganese substituted cobalt ferrite $\left(\mathrm{Co}_{1-\mathrm{x}} \mathrm{Mn}_{\mathrm{x}} \mathrm{Fe}_{2} \mathrm{O}_{4}\right.$ with $\mathrm{x}=0,0.3,0.5,0.7$ and 1) nanoparticles are shown in Fig. 2. The diffraction peak of the reflection plane (3 111 ) of maximum intensity shows that the material has a single face centred cubic spinel phase. The reflection planes (2 20$)$ (3 111$)$ (5 111$)$ (4 40 ) of corresponding diffraction angles $30.26^{\circ}$, $35.5^{\circ}, 56.9^{\circ}, 62.5^{\circ}$ show that all the samples have a cubic spinel structure [13]. The peak shift for the plane $\left(\begin{array}{lll}3 & 1 & 1\end{array}\right)$ is caused by the lattice constant variation with manganese substitution. The lattice constant $\left(\mathrm{a}_{0}\right)$ was calculated from the obtained 'd' value with the respective (h k l) parameters. 
Table 1. Summary of lattice constant values $[\AA]$ for $\mathrm{Co}_{1-\mathrm{x}} \mathrm{Mn}_{\mathrm{x}} \mathrm{Fe}_{2} \mathrm{O}_{4}$ with $\mathrm{x}$ varying from $0.0,0.3$, $0.5,0.7$ and 1.0.

\begin{tabular}{ccc}
\hline No. & Sample & Lattice constant $[\AA]$ \\
\hline \hline 1 & $\mathrm{CoFe}_{2} \mathrm{O}_{4}$ & 8.397 \\
2 & $\mathrm{Co}_{0.7} \mathrm{Mn}_{0.3} \mathrm{Fe}_{2} \mathrm{O}_{4}$ & 8.424 \\
3 & $\mathrm{Co}_{0.5} \mathrm{Mn}_{0.5} \mathrm{Fe}_{2} \mathrm{O}_{4}$ & 8.421 \\
4 & $\mathrm{Co}_{0.3} \mathrm{Mn}_{0.7} \mathrm{Fe}_{2} \mathrm{O}_{4}$ & 8.466 \\
5 & $\mathrm{MnFe}_{2} \mathrm{O}_{4}$ & 8.493 \\
\hline
\end{tabular}

The linear variation of lattice constant ' $\mathrm{a}_{0}$ ' with respect to manganese content is shown in Table 1 . It varies from $8.39 \AA$ to $8.49 \AA$. The lattice constant values of $8.39 \AA$ for $\mathrm{CoFe}_{2} \mathrm{O}_{4}$ and $8.49 \AA$ for $\mathrm{MnFe}_{2} \mathrm{O}_{4}$ closely match with the proposed results [14]. The obtained results show that the increased lattice constant with an increase of manganese content in cobalt ferrite nanoparticles results from the occupying nature of $\mathrm{Mn}^{2+}$ ions whose atomic radius $(0.83 \AA)$ is greater than the atomic radius of $\mathrm{Co}^{2+}$ ions $(0.78 \AA)$ [13]. The average crystalline structure was calculated using Debye Scherrer's formula and it was in the range between $23 \mathrm{~nm}$ to $45 \mathrm{~nm}$.

\subsection{Magnetic measurements}

Magnetic properties of manganese substituted cobalt ferrite nanoparticles were studied by vibrating sample magnetometer (VSM) analysis. The obtained VSM results for different compositions $\left(\mathrm{Co}_{1-\mathrm{x}} \mathrm{Mn}_{\mathrm{x}} \mathrm{Fe}_{2} \mathrm{O}_{4}\right.$ with $\mathrm{x}=$ 0, 0.3, 0.5, 0.7 and 1) of magnetic nanoparticles are shown in Fig. 3. It was found that the coercivity $\left(\mathrm{H}_{\mathrm{c}}\right)$, remanent magnetization $\left(\mathrm{M}_{\mathrm{r}}\right)$ and saturation magnetization $\left(\mathrm{M}_{\mathrm{S}}\right)$ vary for different molar ratios of manganese in the cobalt ferrite nanoparticles. It was observed that the coercivity $\left(\mathrm{H}_{\mathrm{c}}\right)$ and remanent magnetization $\left(\mathrm{M}_{\mathrm{r}}\right)$ decrease with an increase in molar ratio of manganese in cobalt ferrite nanoparticles. The saturation magnetization $\left(\mathrm{M}_{\mathrm{s}}\right)$ starts increasing and decreasing with manganese substitution. The above trend in saturation magnetization $\left(\mathrm{M}_{\mathrm{s}}\right)$ parameter was due to super exchange interaction mechanism between lattice positions of metal ions $\mathrm{A}$ and $\mathrm{B}$ in ferrites [15]. From the obtained results, it was deduced that the substituted $\mathrm{Mn}^{2+}$ ions occupy $\mathrm{A}$ and $\mathrm{B}$ lattice positions, which results in the reduction of interaction between $\mathrm{A}$ and $\mathrm{B}$ sites. The substitution of nonmagnetic ion such as manganese, which has a preferential A site occupancy, results in the reduction of the exchange interaction between A and B sites. Hence, by varying the amount of manganese substitution, it should be possible to vary magnetic properties of the samples. In our study, the preferential occupancy of added manganese $\left(\mathrm{Mn}^{2+}\right)$ reduced the exchange interaction between $\mathrm{A}$ and $\mathrm{B}$ sites due to which the saturation magnetization decreased [16].

\subsection{SEM analysis}

Fig. 4 shows the scanning electron microscope (SEM) images of manganese substituted cobalt ferrite nanoparticles synthesized by coprecipitation method. The reported size of the nanoparticles was in between $88 \mathrm{~nm}$ to $71 \mathrm{~nm}$ which was in close agreement with the general statement that the average grain size of nanocrystalline materials is of the order of 1 to $100 \mathrm{~nm}$. It was found that the grains were connected to each other all over the sample.

\subsection{TG/DTA analysis}

Thermogravimetric (TG) and differential thermal analysis (DTA) graphs are shown in Fig. 5. The TG/DTA analysis was made for the synthesized three powder samples with the compositions $\mathrm{CoFe}_{2} \mathrm{O}_{4}, \mathrm{Co}_{0.7} \mathrm{Mn}_{0.3} \mathrm{Fe}_{2} \mathrm{O}_{4}$ and $\mathrm{Co}_{0.5} \mathrm{Mn}_{0.5} \mathrm{Fe}_{2} \mathrm{O}_{4}$. The DTA curves show the sharp endothermic peak at $110{ }^{\circ} \mathrm{C}$ which may be due to complete removal of moisture and initiation of crystalline structure of the samples. In the TGA curves, the decrement in weight percentage at $100{ }^{\circ} \mathrm{C}$ is due to water loss in the samples. The weight loss for $\mathrm{CoFe}_{2} \mathrm{O}_{4}$ is larger than for $\mathrm{Co}_{0.7} \mathrm{Mn}_{0.3} \mathrm{Fe}_{2} \mathrm{O}_{4}$ and $\mathrm{Co}_{0.5} \mathrm{Mn}_{0.5} \mathrm{Fe}_{2} \mathrm{O}_{4}$. Also $\mathrm{CoFe}_{2} \mathrm{O}_{4}$ shows slow crystallization process from $375^{\circ} \mathrm{C}$ to $800{ }^{\circ} \mathrm{C}$. The results show that manganese substitution decreased the weight loss during the crystallization process. The weight loss between $375{ }^{\circ} \mathrm{C}$ to $400{ }^{\circ} \mathrm{C}$ may be due to the decomposition of impurities present in the samples. The gradual 


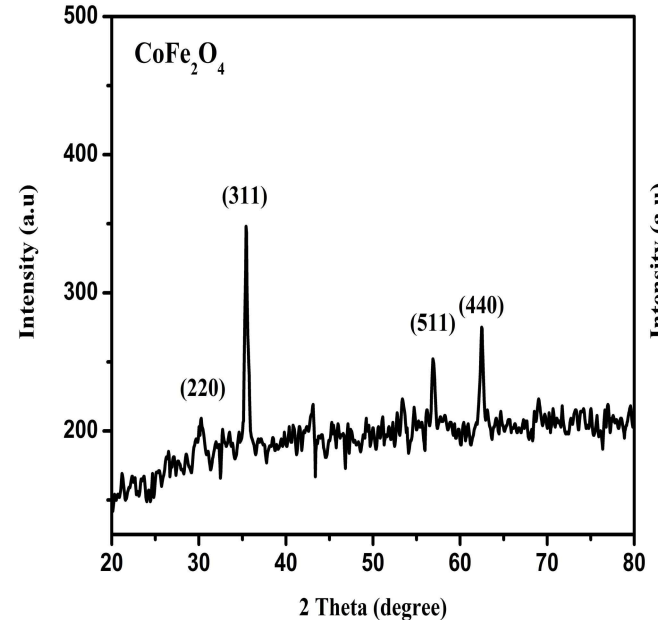

(a)

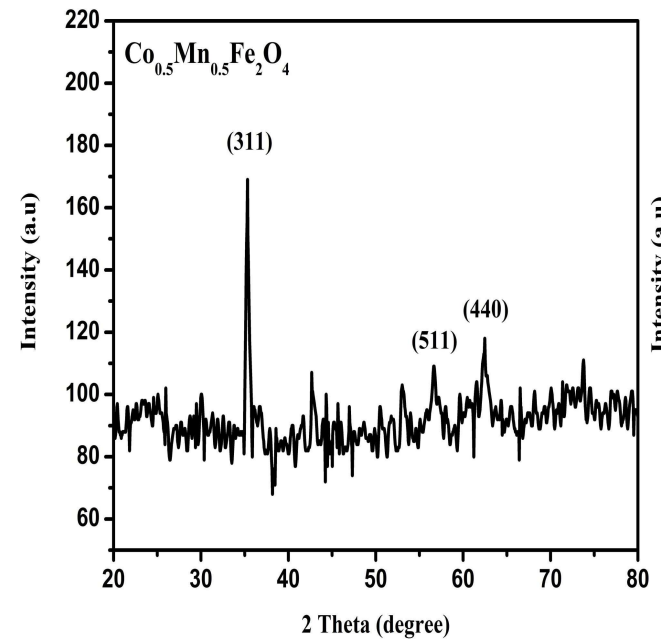

(c)

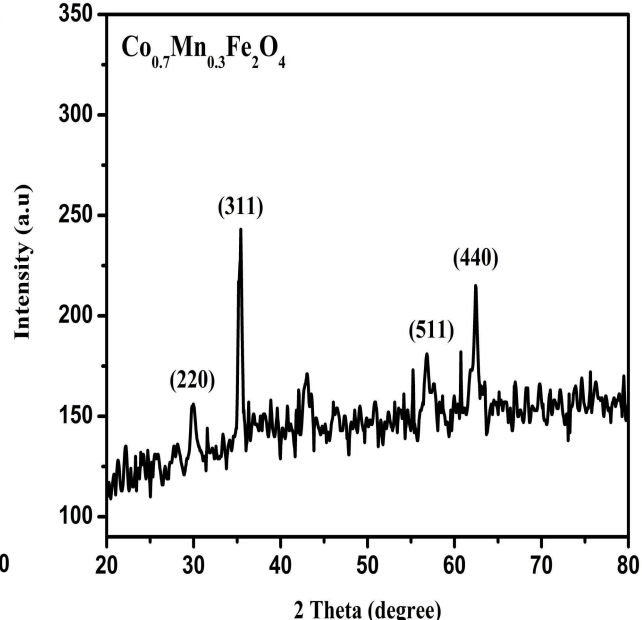

(b)

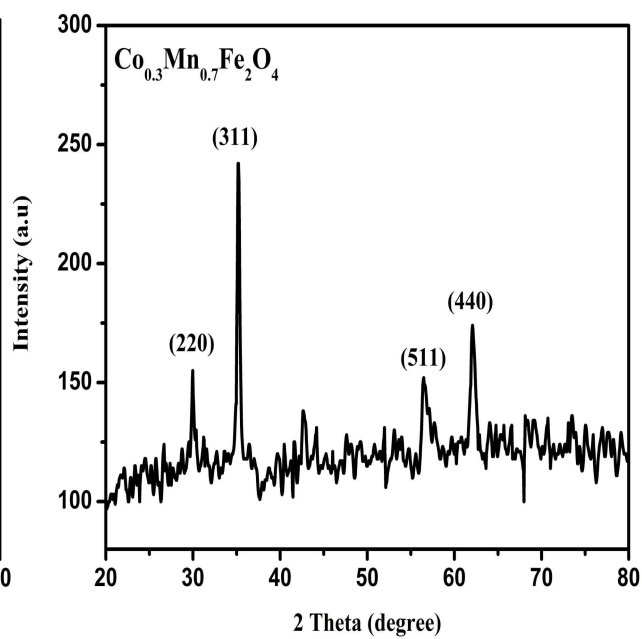

(d)

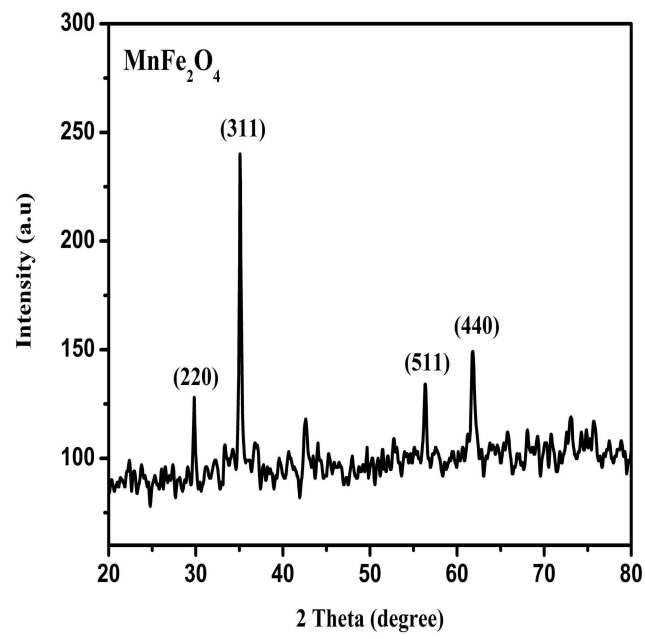

(e)

Fig. 2. Indexed X-ray diffraction patterns of (a) $\mathrm{CoFe}_{2} \mathrm{O}_{4}$, (b) $\mathrm{Co}_{0.7} \mathrm{Mn}_{0.3} \mathrm{Fe}_{2} \mathrm{O}_{4}$, (c) $\mathrm{Co}_{0.5} \mathrm{Mn}_{0.5} \mathrm{Fe}_{2} \mathrm{O}_{4}$, (d) $\mathrm{Co}_{0.3} \mathrm{Mn}_{0.7} \mathrm{Fe}_{2} \mathrm{O}_{4}$ and (e) $\mathrm{MnFe}_{2} \mathrm{O}_{4}$. 


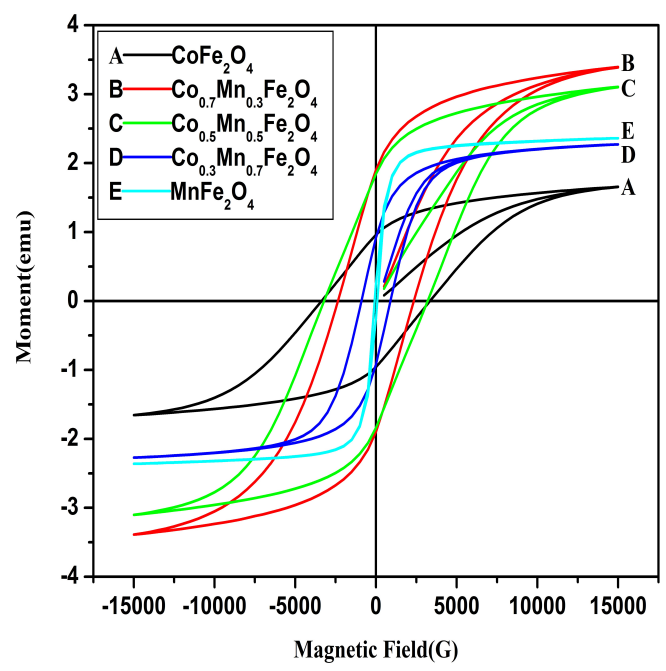

Fig. 3. Magnetization curves of $\mathrm{CoFe}_{2} \mathrm{O}_{4}$, $\mathrm{Co}_{0.7} \mathrm{Mn}_{0.3} \mathrm{Fe}_{2} \mathrm{O}_{4}, \quad \mathrm{Co}_{0.5} \mathrm{Mn}_{0.5} \mathrm{Fe}_{2} \mathrm{O}_{4}$, $\mathrm{Co}_{0.3} \mathrm{Mnn}_{0.7} \mathrm{Fe}_{2} \mathrm{O}_{4}$ and $\mathrm{MnFe}_{2} \mathrm{O}_{4}$ at room temperature.

weight loss in the range of $450{ }^{\circ} \mathrm{C}$ to $800{ }^{\circ} \mathrm{C}$ was due to the formation of crystalline structure in the synthesized samples. The linear weight loss in temperature range of 500 to $800{ }^{\circ} \mathrm{C}$ confirms the complete formation of crystalline and spinel phase structure in the synthesized samples. It can be stated that the removal of adsorbed water and impurities, and formation of complete crystalline structure with spinel phase was completed at $800{ }^{\circ} \mathrm{C}[17,18]$.

\subsection{Comparative analysis on heat trans- fer rate of Co-Mn ferrofluids}

\subsubsection{Aggregation of magnetic nanoparticles in magnetic field}

Ferrofluids are colloidal suspensions of magnetic nanoparticles in a nonmagnetic carrier fluid possessing superparamagnetic nature and exhibiting Brownian motion whose moments are dynamic in nature. In such case, when an external magnetic field is applied, the convection velocity of nanoparticles reduces and results in chain like formation. The Brownian motion of particles almost disappears [19]:

$$
v=\sqrt{18 k_{B} T / \pi \rho d^{3}}
$$

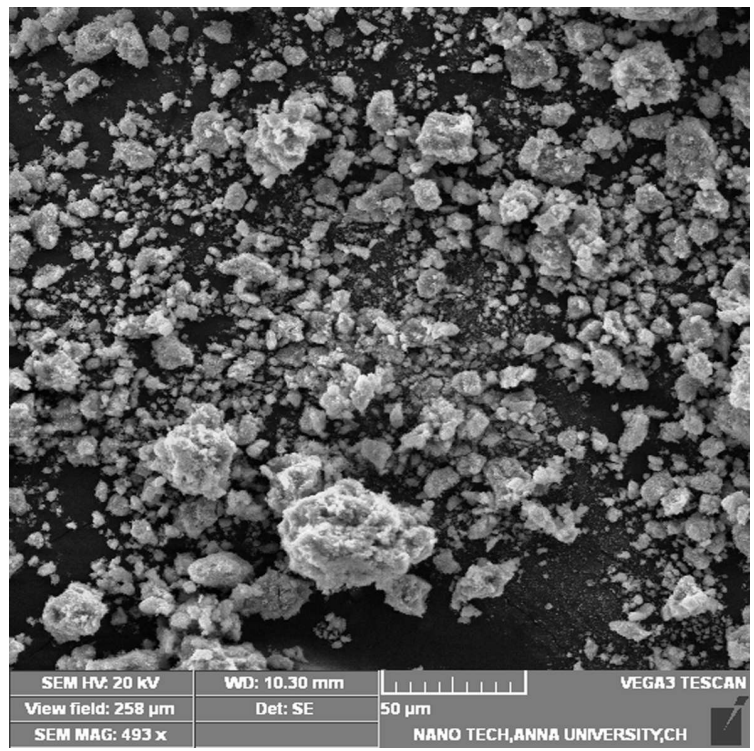

(a)

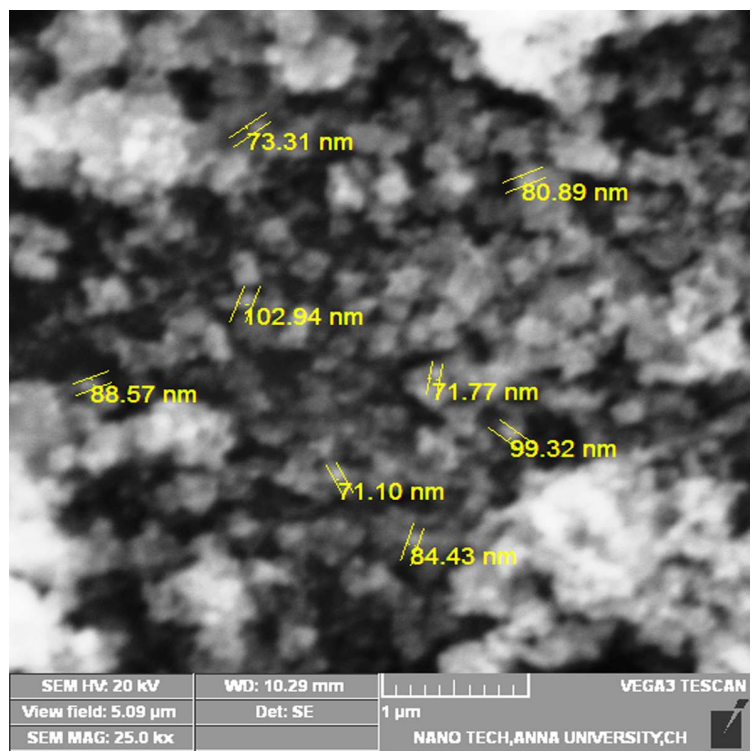

(b)

Fig. 4. SEM images of manganese substituted $\mathrm{CoFe}_{2} \mathrm{O}_{4}$ nanoparticles.

where $k_{B} T$ represents the thermal energy, $\rho$ represents the density of fluid and d represents the diameter of the suspended particles. The aggregation process of the system is governed by the dipoledipole energy between fluctuating moments given as [20, 21]:

$$
U_{d d}(r)=\frac{-1}{3 k_{B} T}\left(\frac{2 m_{1} m_{2}}{\pi \mu_{0} r^{3}}\right)
$$




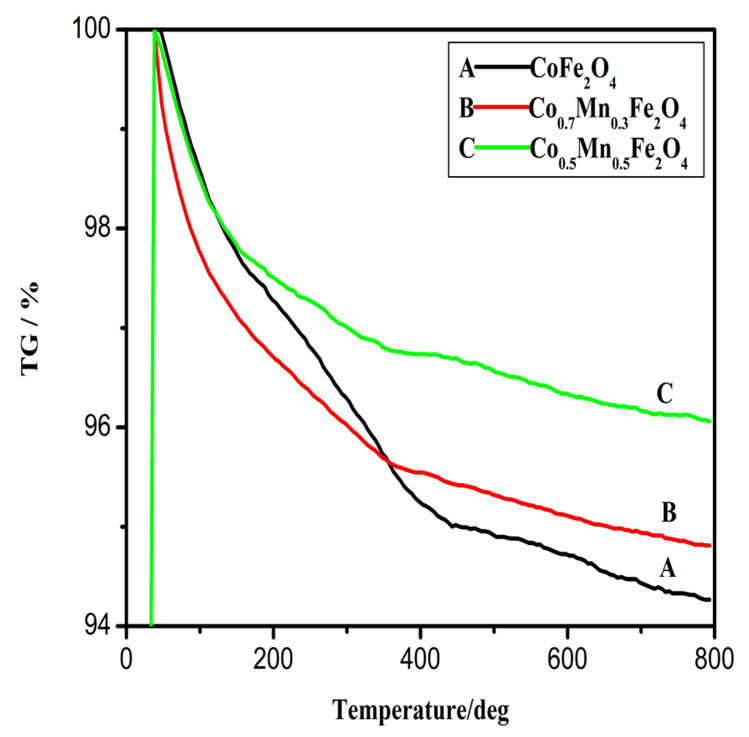

(a)

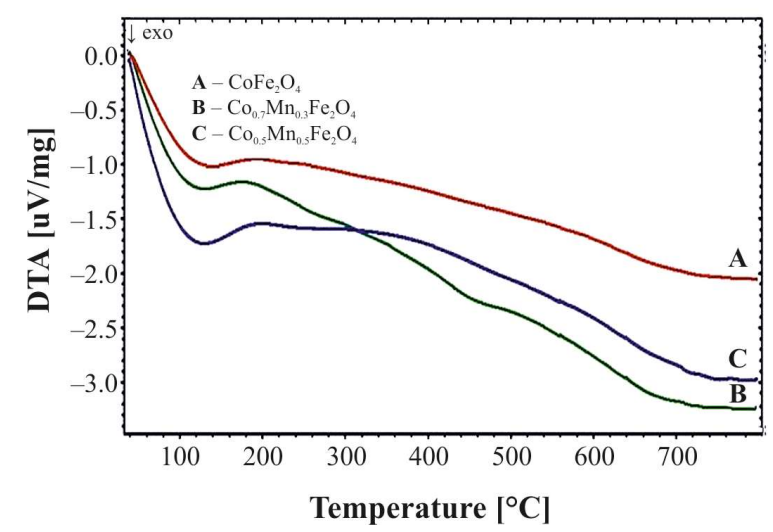

(b)

Fig. 5. (a) TG and (b) DTA results of manganese substituted $\mathrm{CoFe}_{2} \mathrm{O}_{4}$ nanoparticles with $\mathrm{x}=0.0,0.3$ and 0.5 .

where $\mathrm{U}_{\mathrm{dd}}$ is the dipole-diplole interaction energy and $\mu_{0}$ represents permeability of free space. When an external magnetic field is applied, the dipoledipole interaction between the moments increases, resulting in aggregation of particles in direction of the applied magnetic field. The phenomenon is similar to that of an isothermal compression of an ideal gas. The entropy of the system is defined as [21, 22]:

$$
\Delta S=N K_{B} \ln \left(\frac{V_{a}}{V}\right)
$$

where $\mathrm{N}$ and $\mathrm{K}_{\mathrm{B}}$ are the number of magnetic particles and Boltzman constant.

\subsubsection{Comparative analysis}

An experimental analysis was carried out to investigate and compare the heat transfer rate of the ferrofluids in external magnetic fields. The experimental setup was shown in Fig. 1. Manganese substituted cobalt ferrofluid $\left(\mathrm{Co}_{1-\mathrm{x}} \mathrm{Mn}_{\mathrm{x}} \mathrm{Fe}_{2} \mathrm{O}_{4}\right)$ samples: $\mathrm{CoFe}_{2} \mathrm{O}_{4}, \mathrm{Co}_{0.5} \mathrm{Mn}_{0.5} \mathrm{Fe}_{2} \mathrm{O}_{4}$ and $\mathrm{MnFe}_{2} \mathrm{O}_{4}$ were subjected to two external magnetic field of different values. Fig. 6 shows the heat transfer rate of a $\mathrm{CoFe}_{2} \mathrm{O}_{4}$ ferrofluid at external magnetic field generated at two current values of $\mathrm{I}=1.8 \mathrm{~A}$ and $2.7 \mathrm{~A}$. The recorded average heat transfer rates per temperature in ${ }^{\circ} \mathrm{C}$ were $3.5 \mathrm{~s} /{ }^{\circ} \mathrm{C}$ and $1.8 \mathrm{~s} /{ }^{\circ} \mathrm{C}$ respectively. Fig. 7 shows the average heat transfer rates of $\mathrm{Co}_{0.5} \mathrm{Mn}_{0.5} \mathrm{Fe}_{2} \mathrm{O}_{4}$ ferrofluid for the above mentioned two current values which are $3.8 \mathrm{~s} /{ }^{\circ} \mathrm{C}$ and $3.6 \mathrm{~s} /{ }^{\circ} \mathrm{C}$ respectively. Fig. 8 shows the average heat transfer rate per temperature in ${ }^{\circ} \mathrm{C}$ of $\mathrm{MnFe}_{2} \mathrm{O}_{4}$ ferrofluid for the same two current values and the heat transfer rate were $3.6 \mathrm{~s} /{ }^{\circ} \mathrm{C}$ and $2.1 \mathrm{~s} /{ }^{\circ} \mathrm{C}$, respectively.

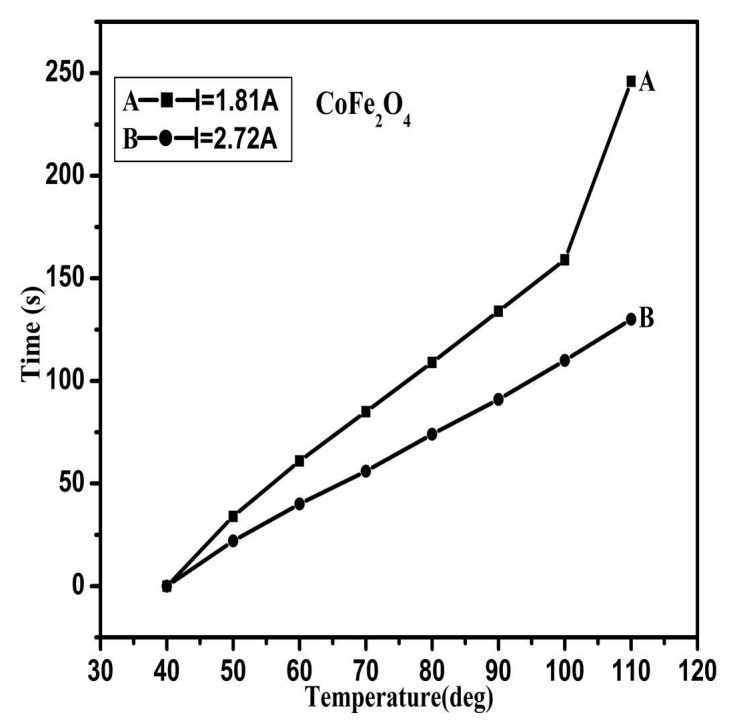

Fig. 6. Heat transfer rate of transformer oil based $\mathrm{CoFe}_{2} \mathrm{O}_{4}$ ferrofluid at an applied external magnetic fields for $\mathrm{I}=1.8 \mathrm{~A}$ and $2.7 \mathrm{~A}$.

Irrespective of the values of applied magnetic field, the heat transfer rate of single domain magnetic nanoparticle dispersed fluids $\left(\mathrm{CoFe}_{2} \mathrm{O}_{4}\right.$ 


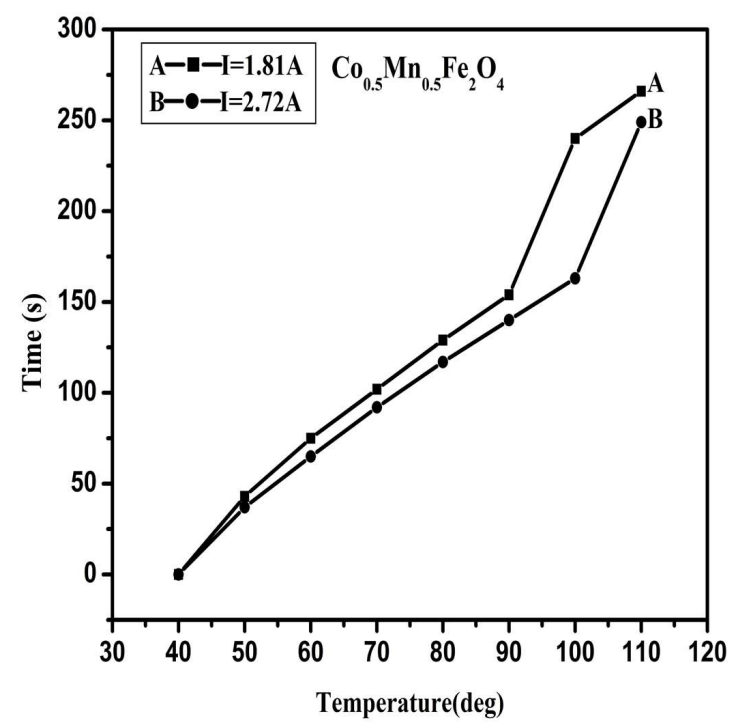

Fig. 7. Heat transfer rate of transformer oil based $\mathrm{Co}_{0.5} \mathrm{Mn}_{0.5} \quad \mathrm{Fe}_{2} \mathrm{O}_{4}$ ferrofluid at an applied external magnetic fields for $\mathrm{I}=1.8 \mathrm{~A}$ and $2.7 \mathrm{~A}$.

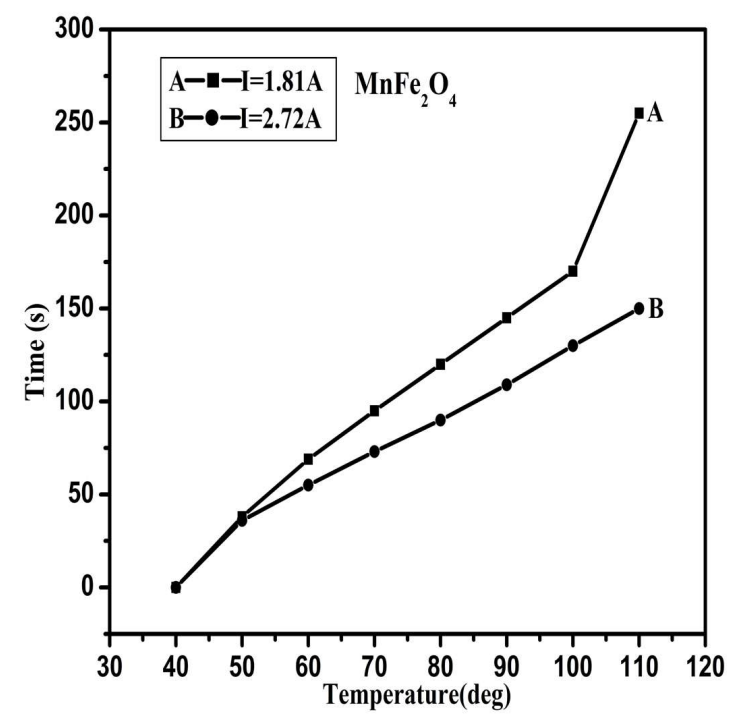

Fig. 8. Heat transfer rate of transformer oil based $\mathrm{MnFe}_{2} \mathrm{O}_{4}$ ferrofluid at an applied external magnetic fields for $\mathrm{I}=1.8 \mathrm{~A}$ and $2.7 \mathrm{~A}$.

and $\mathrm{MnFe}_{2} \mathrm{O}_{4}$ ) was found to be greater than that of polydispersed fluids $\left(\mathrm{Co}_{0.5} \mathrm{Mn}_{0.5} \mathrm{Fe}_{2} \mathrm{O}_{4}\right)$. In both single domain and polydispersed magnetic nanoparticle dispersed fluids, the strength of the applied alternating magnetic field plays an important role in the heat transfer rate. The heat transfer rate for $\mathrm{I}=1.8 \mathrm{~A}$ did not exhibit significant variation among the three samples. Nkurikiyimfura et al. [6] found that the thermal conductivity of polydispersed magnetic nanoparticle dispersed fluid was lower than that of single domain magnetic nanoparticle dispersed fluids. It was shown that the multi domain ferro/ferri magnetic nanoparticles dispersed ferrofluids could lead to poor stability of $\mathrm{MNF}_{\mathrm{S}}$ due to their long and irreversible chain-like structures.

The heat transfer rate analysis results of manganese substituted cobalt ferrofluids $\left(\mathrm{Co}_{1-\mathrm{x}} \mathrm{Mn}_{\mathrm{x}} \mathrm{Fe}_{2} \mathrm{O}_{4}\right.$ with $\mathrm{x}=0.0,0.5$, and 1$)$ of different molar ratios were similar to the results reported by Wang et al. [4]. He proposed that the mixture of magnetic and non-magnetic nanoparticle dispersed carrier fluid promotes thermal conductivity.

The heat transfer rates of $\mathrm{CoFe}_{2} \mathrm{O}_{4}, \mathrm{MnFe}_{2} \mathrm{O}_{4}$ and $\mathrm{Co}_{0.5} \mathrm{Mn}_{0.5} \mathrm{Fe}_{2} \mathrm{O}_{4}$ were greater for $\mathrm{I}=2.7 \mathrm{~A}$ than for $\mathrm{I}=1.8 \mathrm{~A}$. The result indicates that the heat transfer rate strongly depends upon the strength of the applied external magnetic field. Similar results have been reported by Shima et al. [8] and Lian et al. [23]. They showed that the enhancement of thermal conductivity can be observed in magnetic nanofluids with increasing strength of applied alternating magnetic field in its parallel direction to the temperature gradient.

The heat transfer rate of polydispersed magnetic nanofluid $\mathrm{Co}_{0.5} \mathrm{Mn}_{0.5} \mathrm{Fe}_{2} \mathrm{O}_{4}$ was lesser than the heat transfer rate of single domain magnetic nanoparticle dispersed fluids $\mathrm{CoFe}_{2} \mathrm{O}_{4}$ and $\mathrm{MnFe}_{2} \mathrm{O}_{4}$ for both applied alternating magnetic field values: $\mathrm{I}=1.8 \mathrm{~A}$ and $\mathrm{I}=2.7 \mathrm{~A}$. This result was in coincidence with the proposed result of Nkurikiyimfura et al. [6].

\subsection{Applications}

Lian et al. reported that synthesized magnetic nanofluids were used in automatic energy transport cooling devices in which thermal conductivity enhancement occurred along with removal of heat, when such devices were immersed in magnetic nanofluids [23]. It was also reported that the MNF layer of $10 \mathrm{~mm}$ thickness absorbed completely solar radiation and acted as a good heat 
transfer medium in solar panel constructions [24]. This research suggests that the single domain magnetic nanoparticle dispersed fluids $\mathrm{CoFe}_{2} \mathrm{O}_{4}$ and $\mathrm{MnFe}_{2} \mathrm{O}_{4}$ could be used in heat transport phenomena. They can be more suitable for electrical devices, such as transformers, smart cooling devices and automatic energy transport systems due to their high heat transfer rate as compared to poly dispersed magnetic nanofluid sample $\mathrm{Co}_{0.5} \mathrm{Mn}_{0.5} \mathrm{Fe}_{2} \mathrm{O}_{4}$. Magnetic nanofluids may give promising results of enhanced heat transfer rate in smart cooling and thermal conduction devices as compared to conventional fluid based devices.

\section{Conclusions}

Manganenese substituted cobalt ferrite $\left(\mathrm{Co}_{1-\mathrm{x}} \mathrm{Mn}_{\mathrm{x}} \mathrm{Fe}_{2} \mathrm{O}_{4}\right.$ with $\mathrm{x}=0.0,0.3,0.5,0.7$ and 1) nanoparticles were successfully synthesized using chemical coprecipitation method. The structural, magnetic, morphological and thermal properties of the prepared samples were analyzed using XRD, VSM, SEM and TG/DTA. XRD results confirmed that all the prepared magnetic nanoparticle powder samples had a cubic spinel structure. TG/DTA analysis showed the removal of adsorbed water, impurities and formation of complete crystalline structure of the samples with spinel phase. From VSM analysis, it was concluded that the coercivity $\left(\mathrm{H}_{\mathrm{c}}\right)$ and remanent magnetization $\left(\mathrm{M}_{\mathrm{r}}\right)$ decrease with an increase in molar ratio of manganese substituted cobalt ferrite nanoparticles. Homogeneous magnetic nanofluids with manganese substituted cobalt ferrite nanoparticles of different molar ratios dispersed in transformer oil were prepared. The heat transfer analysis was carried out in the prepared magnetic nanofluids in external magnetic fields. The obtained results showed that the single domain magnetic nanoparticles dispersed fluids $\left(\mathrm{CoFe}_{2} \mathrm{O}_{4}\right.$ and $\left.\mathrm{MnFe}_{2} \mathrm{O}_{4}\right)$ exhibited enhanced heat transfer rate in comparison to poly dispersed magnetic nanofluid $\left(\mathrm{Co}_{0.5} \mathrm{Mn}_{0.5} \mathrm{Fe}_{2} \mathrm{O}_{4}\right)$ for the two different applied external magnetic fields. The rate of heat transfer depended upon the strength of the applied external magnetic field. It was concluded that the manganese substituted cobalt ferrofluids $\left(\mathrm{Co}_{1-\mathrm{x}} \mathrm{Mn}_{\mathrm{x}} \mathrm{Fe}_{2} \mathrm{O}_{4}\right)$ of different molar ratios can be utilized in energy convention devices, transformers, smart cooling devices, and in automatic energy transport devices.

\section{Acknowledgements}

One of the author. S. Sendhilnathan, gratefully acknowledges the DST (Ref. No. SERC No. 100/IFD/7194/201011 dated on 12.10.10) for the financial assistance received through the project.

\section{References}

[1] Murty B.S., The Big World of Nanomaterials, in: Murty B.S., Shankar P., Raj B., Rath B.B., MURDAY J., Textbook of Nanoscience and Nanotechnology, Springer Berlin Heiderberg, India, 2013, p. 1.

[2] Sharifi I., Shokrollahi H., Amiri S., J. Magn. Magn. Mater, 6 (2012), 903.

[3] Abareshi M., Goharshadi E.K., Zebarjad S.M., FADAfan H.K., Youssefi A., J. Magn. Magn. Mater. 24 (2010), 3895.

[4] Wang X., XU X., Choi S.U.S., J. Thermophys Heat Transfer, 4 (1999), 474.

[5] Philip J., Shima P.D., RaJ B., Appl. Phys. Lett., 20 (2007), 203108-1.

[6] Nkurikiyimfura I., WAng Y., PAn Z., Renew. Sust. Energy. Rev., 21 (2013), 548.

[7] Hong T.K., Yang H.S., Choi C.J., J. Appl. Phys., 6 (2005), 064311-1.

[8] Shima P.D., Philip J., J. Phys. Chem. C., 41 (2011), 20097.

[9] Philip J., Shima P.D., RaJ B., Nanotechnology, 30 (2008), 305706.

[10] Vaidyanathan G., Sendhilnathan S., ArulmuRUGAN R., J. Magn. Magn. Mater., 2 (2007), 293.

[11] Vaidyanathan G., Sendhilnathan S., J. Magn. Magn. Mater, 6 (2008), 803.

[12] JENKIns R., SNYDER R.L., Introduction to X-ray Powder Diffractometry, John Wiley \& Sons Inc, New York, 1996.

[13] Atif M., Turtelli R.S., Grossinger R., SiDDiQue M., NADEem M., Ceram. Int., 1 (2014), 471.

[14] Pereira C., Pereira A.M., Fernandes C., Rocha M., MENDES R., GARCÍA M.P.F., Guedes A., TAVARES P.B., Greneche J.M., Araujo J.P., Freire C., Chem. Mater., 8 (2012), 1496.

[15] Yadav S.P., Shinde S.S., Bhatt P., Meena S.S., Rajpure K.Y., J. Alloy. Compd., 646 (2015), 550.

[16] SaAfan S.A., Assar S.T., Mansour S.F., J. Alloy. Compd., 542 (2012), 192.

[17] Sanpo N., Berndt C.C., Wen C., Wang J., Acta Biomater, 3 (2013), 5830.

[18] Hashim M., Alimuddin, Shirsath S.E., KuMar S., Kumar R., Roy A.S., Shah J., Kotnala R.K., J. Alloy. Compd., 549 (2013), 348.

[19] Philip J., Shima P.D., RaJ B., Appl. Phys. Lett., 4 (2008), 043108-1. 
[20] Bishop K.J.M., Wilmer C.E., SOH S., GRZYBOWSKI B.A., Small, 14 (2009), 1600.

[21] NkurikiYimfura I., WAng Y., PAN Z., Exp. Therm. Fluid Sci., 44 (2013), 607.

[22] Li J., Huang Y., LiU X., Lin Y., Bai L., Li Q., Sci. Technol. Adv. Mat., 6 (2007), 448.

[23] LiAn W., XUAN Y., Li Q., Energ. Convers. Manage., 1 (2009), 35.
[24] Luminosu I., Sabata C.D., Sabata A.D., JURCA T., AGIR Sci. Bull., 2 - 3 (2009), 66.
Received 2015-11-25

Accepted 2016-02-28 